\author{
D. J. Hoffman, F. W. Baity, W. E. Bryan, G. L. Chen, K. H. Luk, T.L. Owens, \\ J. M. Ray. P. M. Ryan, D. W. Swain. and J. C. Walls \\ Oak Ridge National Laboratory. P. O. Box Y. Oak Ridge, TN 37831
}

\begin{abstract}
The Oak Ridge National Laboratory is designing. fabricating, and testing antennas for TFTR and Tore Supra. The antennas will deltver $4 \mathrm{MW}$ per port to the hot plasma. The antennas' designs are nearly complete; they are backed by the results of extensive modeling, analyses, and tests of the electrical, thermal. and structural characteristics of the antennas that were carried out during the design process.
\end{abstract}

\title{
INTRODUCTION
}

The designs for these two antennas are approximately equivalent in principle; Tore Supra's design is more complicated because of its longer pulse length, wider frequency range, and higher power density. Table I lists the design parameters for both antennas. Figure 1 shows the layout of the antennas (specifically, of the TFTR antenna). Each antenna consists of a pair of resonant double loops, separated by a solid dividing wall, in a single, movabie housing designed to fit through a horlzontal midplane port (approximately $60 \times 70-90 \mathrm{~cm}$ ). Each loop is designed to launch up to $2 \mathrm{MW}$ of power for a total of $4 \mathrm{MW}$ per port. The TFTR antenna will operate at 40-80 $\mathrm{MHz}$ in two bands; the Tore Supra antenna, at 35-80 $\mathrm{MHz}$ in a single band. Both are tuned to the frequency of operation and matched to the correct impedance ( $50 \Omega$ for TFTR and $30 \Omega$ for Tore Supra) by means of pairs of capacitors. The capacitors for TFTR were designed at ORNL to minimize electric fields at the expense of tuning range, and those for Tore Supra were designed by Comet, Ltd., for higher electric fields and broad tuning capabilities. On both antennas, a single Faraday shield structure protects the loops. The Faraday shield consists of two tiers of actively cooled inconel tubes: the front tier is covered with semicircular graphite sleeves to minimize the introduction of high- $Z$ impurities into the plasma from the Faraday shield. The TFTR antenna is designed for 2-s pulses; the Tore Supra antenna must sustaln 210-s pulses. Plans are to install the TFTR antenna in August 1987 and the Tore Supra antenna in March 1988.

\section{ANTENNA DESIGN}

The electrical circuitry of the two antennas is identical. The current strap is separated from the Faraday shield by $1.5 \mathrm{~cm}$ : the width of the current strap is half that of the enclosing cavity: the side walls are solid to minimize plasma nowing by the strap; and the back piane is at least $15 \mathrm{~cm}$ from the current strap. For this configuration, the characteristic (measured and calculated) impedance for the strap is 65-70 $\Omega$ and the phase velocity is approximately $0.65-0.70$ times the speed of light. From a distributed. lossy coaxial transmission line model (Fig. 2). the voltages and currents on various elements (Fig. 3) have been computed as functions of plasma load for a given antenna power. The load needed to achieve $2 \mathrm{MW}$ (due to voltage or current limits) scales roughly as the square of the frequency. At $6 \Omega / \mathrm{m}, 47 \mathrm{MHz}$. and $2 \mathrm{MW}$ per strap, the capacitor voltages are at the design limit of $50 \mathrm{kV}$ ar.d the electric field between the Faraday shield and current strap is $23 \mathrm{kV} / \mathrm{cm}$. This

Research sponsored by the Office of Fusion Energy. U.S. Department of Energy, under contract DE-ACO5-84OR2 1400 with Martin Marletta Energy Systems, Inc.

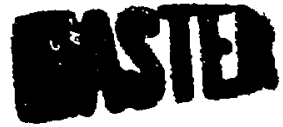


Table 1. Antenna design parameters

\begin{tabular}{lll}
\hline \multicolumn{1}{c}{ Description } & TFTR & Tore Supra \\
\hline Power into the jort (MW) & 4 & \\
Power per current strap (MW) & 2 & 4 \\
Port dimensiori (cm x cm) & $60 \times 90$ & 2 \\
Total frequency range (MHz) & $40-80$ & $60 \times 70$ \\
Frequency rarige, first band (MHz) & $40-60$ & $35-80$ \\
RF pulse length (s) & 2 & $35-80$ \\
Capacitor designer & ORNL & 210 \\
Capacitor voltage (kV peak) & 50 & Cornet \\
Capacitor current (A rms) & 800 & 50 \\
Capacitor electric field (kV/cm) & 43 & 750 \\
Antenna electric fleld (kV/cm) & 23 & 100 \\
Faraday shield losses (W/cm $\left./ \mathrm{cm}^{2}\right)$ & 100 & 23 \\
Antenna power density (W/ $\left./ \mathrm{cm}^{2}\right)$ & 1160 & 100 \\
Antenna notion range. $(\mathrm{cm})$ & 11 & 1520 \\
& & 30 \\
\hline
\end{tabular}

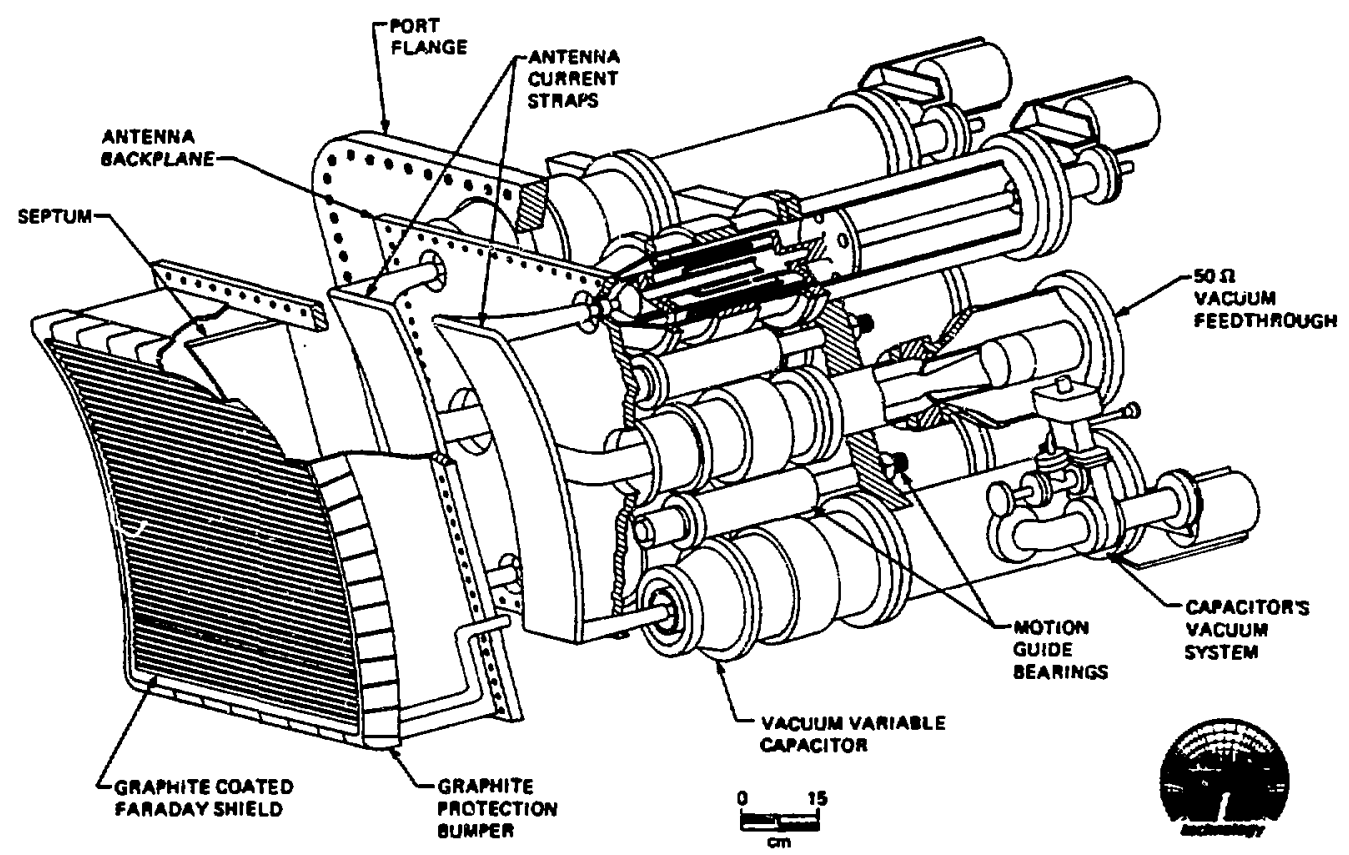

Fig. 1. The antenna for TFTR. 


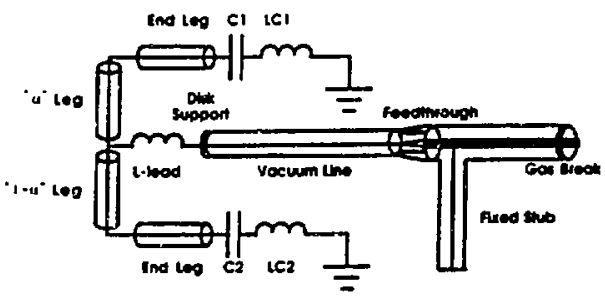

Fig. 2. The electrical circult of the antennas. Because TFTR's current strap is not cooled, its circuit does not have the fixed stub.

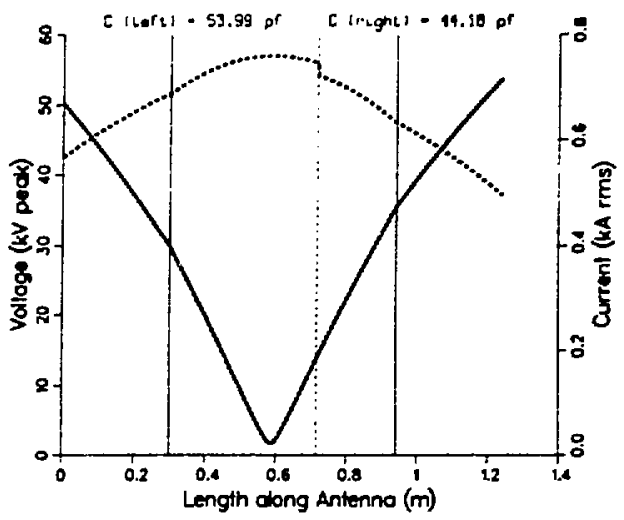

Fig. 3. Voltages and currents along the current strap. The $\mathrm{Cl}$ capasttor in Fig. 2 is at $0 \mathrm{~m}$. The two vertical lines represent the beginning and end of the current strap, and the dashed vertical line is at the site of the feed point. This calculation is for the TFTR antenna with $2 \mathrm{MW}$ at $47 \mathrm{MHz}$ and a load of $6 \Omega / \mathrm{m}$.

fleld has been sustained in the Radio-Frequency Test Facility (RFTF) in the presence of plasma, magnetic fields, and gas on an antenna with the same nominal dimensions and a graphite Faraday shield.

In the circuit, the element most likely to limit power is the vacuum capacitor. The capacitors form a number of concentric, nested, ganged cylinders, as shown in Fig. 1. The capacitance is varled by changing the distance between cylinders. This motion is accommodated in the ORNL design by the use of finger stock to maintain good electrical connections and in the Comet design by cooled bellows. Each capacitor for TFTR has its own vacuum pump: the Comet capacitor is permanently sealed under high vacuum.

The voltage limit is probably determined by two characteristics: the electric field attainable on the ceramic barrier and that attainable between concentric cylinders. Capacitors have been tested in RFTF for electric fields up to $120 \mathrm{kV} / \mathrm{cm}$ between cylinders. For TFTR, only $43 \mathrm{kV} / \mathrm{cm}$ is needed for $50-\mathrm{kV}$ operation: $100 \mathrm{kV} / \mathrm{cm}$ is needed for Tore Supra. The limitation caused by the ceramic has not yet been tested on the Comet capacitor: however, the configuration of the ceramic has been demonstrated to work at voltage levels beyond $70 \mathrm{kV}$ on the ORNL capacitor.

The longer pulse length of the Tore Supra antenna provides more heating in the capacitor than does the relatively short pulse of TFTR. The Comet capacitor has carrled $750 \mathrm{Arms}$ at $80 \mathrm{MHz}$ in steady state, thus dernonstrating the adequacy of the design. The final production models of each capacitor will be tested to prove their acceptability.

The Faraday shields for these antennas must survive in the plasma edge environment. Although Faraday shield losses were measured to be $-0.15 \Omega / \mathrm{m}$ at $47 \mathrm{MHz}$, the shield is designed to handle losses of $0.5 \Omega / \mathrm{m}$. Additional thermal loads on the antenna include plasma radiation and disruption loads. Average design heat fluxes amount to $-150 \mathrm{~W} / \mathrm{cm}^{2}$. Both shields are therefore actively cooled. The design for Tore Supra spectiles cooling water at $40 \mathrm{bar}$ and $170^{\circ} \mathrm{C}$; that for TFTR, 8 bar at $20^{\circ} \mathrm{C}$. The tubes for Tore Supra will conform to the toroidal curvature of the plasma. The TFTR antenna has uncurved tubes, as 
shown in Fig. 1. High stresses in the Faraday shields, resulting from thermal loads and disruption mechanical forces, require that the shields be made of a very strong material. Inconel 600 was chosen for TFTR, and Inconel 625 was used for Tore Supra. The welds that attach the tubes to the frame in the TFTR antenna are designed to a stress level that is $-35 \%$ of the yield stress of Inconel 600 . The tubes themselves are at stresses of up to $\sim 70 \%$ of the yield stress. Thermally induced stresses are $\sim 60 \%$ of the maximum principal stress. Because this is a secondary stress, the tubes can be operated closer to yleld. Use of Inconel 625 holds all stresses below $50 \%$ of yield.

Surrounding the Faraday shield frame is a set of graphite bumper Iimiters that protect the antenna structure. The toroldal energy flow in the tokamak's plasma edge requires these bumper limiters to withstand heat fluxes up to $2 \mathrm{~kW} / \mathrm{cm}^{2}$ with a radial decay length of $1.5-2.5 \mathrm{~cm}$. The shorter pulse length of the TFTR plasma permits some inertial cooling; the long pulse length of Tore Supra does not. The design for TFTR has $\approx 1-\mathrm{cm}$-thick graphite tiles bolted to the Faraday shield cooling manifold. Tests have shown that these tiles can withstand $150 \%$ of the total energy deposit at 7.5 times the tokamak repetition rate. The design for Tore Supra calls for brazing thin (3-mm) pleces of graphite to ganged cooling tubes.

The principles for antenna motion and disruption torque handing are the same for both antennas, but the implementations are different, because of differences in tokamak vacuum vessel geometry. Both antennas sustain forces of $124 \mathrm{kN}$ at four motion bearings. In TFTR, the bearings are Inconel 718 rods displaced off center of the port. A 2-in. buttress-threaded rod is used to move the antenna relative to the plasma. This rod aiso supports radial disruption loads (equivalent to $=2-3$ bar of pressure) and vacuum loads. The Tore Supra design has two port-mounted guide bearings and two externally mounted rods. The external rods will be used to move the antenna. A single large bellows isolates the moving parts from the fixed parts in Tore Supra. Several smaller bellows around the capacitors and feedthroughs perform this function in TFTR.

Although all components have been or will be tested separately, the completed antennas will be tested on the RFTF before the final application. Primarily, the tests are intended to prove that the antennas can sustain full current and full voltage in the presence of gas, magnetic fleld. and plasma. Thermal cycling of the critical Faraday shield elements is required to ensure structural integrity. Finally, operational techniques for handling these specific antennas will be developed.

\section{CONCLUSIONS}

The 4-MW antennas for TFTR and Tore Supra are based on designs that have balanced the electrical requirements, thermal loads, disruption forces, and mechanical constraints. Many tests and analyses have been made to ensure that these antennas will work and be reliable. The design and testing have yielded important benefits: (1) development of a graphite plasma interface to minimize impurities. (2) development of tunable. matched antennas, (3) elimination of the requirement that plasma boundaries be configured around antenna needs, and (4) the confidence that testing affords. 